\title{
$\mathrm{SW}$ 공학수준과 SW 프로젝트 납기성과와의 관계
}

\author{
김승권* · 고병선**
}

\section{Evaluation on the Relationship between Software Engineering Level and Schedule Deviation in Software Development}

\author{
Seung-Gweon Kim* · Byung-Sun Ko**
}

\begin{abstract}
Recently, many software companies are trying to improve the software quality and project outcome with more costs and efforts in development time. In the software convergence and integration environments, it is required efforts to gain high quality of software. In other words, it is required to utilize software engineering knowledge and technology for higher software quality and better software project productivity. The Software development productivity can be varied by software process capability according to building a framework for software development, selection and use of appropriate technology, human resource management. Software process capability will influence software project outcome which is the general opinion.

This study provides empirical evidence about software engineering efforts and investment approach to lead software project performance. We measured the software engineering efforts by SW engineering level and analyzed the corelation between software engineering level and schedule deviation. And, we verified that this performance is affected by the size of software company. As a result, software process capability is important to build a infrastructure and develop systematically software project. The higher software engineering level can lead to improved software project performance.
\end{abstract}

Keyword : SW Engineering Level, SW Process, Negative binomial regression, Schedule Deviation

\footnotetext{
논문투고일 : 2011년 07월 29일논문수정완료일 : 2011년 10월 21일 논문게재확정일 : 2011년 11월 07일 * 정보통신산업진흥원 SW공학센터 수석연구원

** 정보통신산업진흥원 $\mathrm{SW}$ 공학센터 책임연구원
} 


\section{1. 서 론}

정보기술(IT : Information Technology) 산업과 다른 산업과의 융 - 복합이 빠르게 발전하면서, 소 프트웨어(SW)와 $\mathrm{SW}$ 가 제공하는 서비스에 대한 의존도가 높아지고 있으며, 더불어 $\mathrm{SW}$ 품질에 대 한 요구가 증가하고 있다. 이와 더불어, 글로벌 IT 시장에서 경쟁이 치열해짐에 따라, $\mathrm{SW}$ 기업들은 개발 기간을 단축하면서 결함 없는 $\mathrm{SW}$ 를 고객에 게 전달할 수 있는 경제효율적인 부분에 대한 관 심이 높아지고 있다[1].

$\mathrm{SW}$ 개발 프로젝트의 목표는 주어진 일정과 비용 으로 고객이 요구하는 기능을 갖추고, 품질이 좋은 시스템을 개발하는 것이다. 2009년 Standish Chaos Report에 따르면, 미국내에서 수행된 SW 프로젝 트 중에서 납기와 비용을 준수하고 고객이 요청한 특징과 기능을 갖춘 성공적인(successful) 프로젝 트가 $32 \%$, 요구사항 충족 부족이거나 납기 또는 비 용 초과인 도전(challenged) 프로젝트는 44\%, 중 간에 중단되거나 사용되지 못한 실패(failed) 프로 젝트는 $24 \%$ 인 것으로 조사되었다[3].

$\mathrm{SW}$ 프로젝트 성공에 대한 궁극적인 의미는 $\mathrm{SW}$ 프로젝트가 완료된 이후 예상되는 비즈니즈 변화 와 이에 대응하는 가치를 제대로 전달하거나 반영 가능한 프로젝트여야 보다 완벽한 $\mathrm{SW}$ 프로젝트 성공이라 할 수 있을 것이다. 이러한 성공적인 SW 프로젝트를 위한 기본은 SW 개발 및 운영, 유지 보수, 관리 등에 필요한 체계 및 절차를 확립하고 $\mathrm{SW}$ 공학적 접근방식을 적용하여 보다 체계적이 며 예측가능하게 소프트웨어를 개발하는 것이다.

$\mathrm{SW}$ 프로젝트의 성공률을 높이는 방안중 하나가 $\mathrm{SW}$ 공학기술을 체계적으로 적용하여 $\mathrm{SW}$ 를 개 발하고 관리하는 것이다. $\mathrm{SW}$ 공학의 적용은 안정 적이며 신뢰성 있는 $\mathrm{SW}$ 를 효율적으로 생산하기 위해 절차, 방법, 기술, 인프라, 인력 등 여러 측면 에서 체계적인 활동을 통해 높은 품질의 SW 생산 과 $\mathrm{SW}$ 개발의 생산성 향상을 의미한다. 또한 성 공적인 SW 프로젝트를 위해서는 프로젝트 목표
명확화, 업무범위 변경관리, 품질관리, 위험관리, 인 력관리 등 보다 폭넓은 프로젝트 관리가 이루어져 야 한다[20]. 하지만, 불명확한 요구사항, 복잡한 개발과정 및 개발과정의 비가성으로 인한 관리의 어려움 때문에 $\mathrm{SW}$ 개발 프로젝트의 실패 위험성 은 다른 산업의 제품 개발에 비해 높다.

$\mathrm{SW}$ 개발 시 최종 SW 품질 확보는 물론 중요하지 만 정해진 일정이 충족된 $\mathrm{SW}$ 개발이 선행되어야 한다. 즉, 아무리 좋은 기능의 SW 제품이라도 적시 에 개발되어 고객이나 시장에 전달되지 않는다면, $\mathrm{SW}$ 기업들의 비용 손실로 이어지기 때문이다. 따 라서 일정과 비용을 준수하면서 높은 품질의 $\mathrm{SW}$ 제품을 개발하기 위해서는 SW 기업들의 개발능 력을 높이기 위한 노력이 필수적인 요소이다.

많은 $\mathrm{SW}$ 기업들은 자신들의 $\mathrm{SW}$ 제품의 품질향 상과 더불어 주어진 납기 및 비용을 준수하고, 제 품을 적시에 출시하기 위해 $\mathrm{CMM}$ (Capability $\mathrm{Ma}^{-}$ turity Model Integration)나 ISO/IEC 15504(SPICE: Software Process Improvement and Capability dEtermination)와 같은 SW 프로세스 개선활동을 추진하고 있다. 이런 개선활동에 많은 비용과 인 력이 소요된다는 점을 고려하면, $\mathrm{SW}$ 프로세스 역 량수준과 SW 프로젝트 성과에 대한 객관적인 증 거를 제시하는 일은 매우 중요하다. 이는 SW 프 로세스 역량 개선활동을 위해서 투입하는 비용이 나 노력에 대한 정량적인 근거를 제시할 수 있게 된다.

따라서 본 연구의 목적은 국내 SW 기업들의 SW 공학역량과 SW 프로젝트의 성과변수인 납기성과 와의 관계를 실증 데이터를 통해 분석하는 것이다. 또한 이러한 SW 프로젝트의 성과가 기업의 규모 에 따라 영향을 받는지를 분석하는 것이다.

본 논문의 구성은 다음과 같다. 제 1 장에서는 서 론과 소프트웨어공학수준과 생산성 향상에 대한 접근법에 대해 살펴보았고, 제 2장 관련연구에서 는 소프트웨어 공학수준 조사 분석과 $\mathrm{SW}$ 프로세 스 개선 사례에 대해 소개하였다. 제 3장에서는 기 존의 연구를 기반으로 본 연구의 연구모델과 연구 
가설을 설정하였다. 제 4장에서는 연구 데이터 수 집과 연구모델의 측정지표들을 정의하였다. 제 5 장에서는 본 연구에서 사용된 분석방법과 분석결 과를 제시하고 있으며, 마지막으로 제 6장에서는 연구 내용의 결론 및 연구의 한계점을 기술하였다.

\section{2. 관련 연구}

\subsection{SW 공학수준의 개요}

$\mathrm{SW}$ 는 인간이 개발한 다른 산업의 제품과 다른 특성을 갖는다. SW 를 개발하는 과정은 흔히 건 축과 많이 비교하는데 빌딩과 같은 구체적인 형태 가 없는 비가성, 개발과정이 복잡하고 표준화되지 않음으로서 나타나는 복잡성, 사용자의 요구나 환 경변화에 따라 변형되어야 하는 순응성, 사용함에 따라 마모되거나 소멸되지 않는 비마모성 등과 같 은 SW 특성들이 존재한다. 특히, SW 의 비가시 성이나 복잡성과 같은 특성들로 인해서 $\mathrm{SW}$ 개발 프로젝트를 관리하는데 어려움을 겪고 있다.

이러한 SW 특성을 체계적으로 관리하기 위한 접 근방법이 SW 공학의 적용이다[21]. SW 공학의 정의는 연구자에 따라 다르지만, $\mathrm{SW}$ 개발 및 관 리 과정에 관련된 지식으로 프로그래밍 언어, 개 발방법론, 품질관리, 프로세스, 인력관리, 설계기 술, 코딩 등 SW 개발 및 관리 과정의 활동에 대한 지식을 체계적으로 정리한 것으로 인식되고 있다.
많은 $\mathrm{SW}$ 기업들은 $\mathrm{SW}$ 공학 적용을 통해 $\mathrm{SW}$ 개발생산성 및 $\mathrm{SW}$ 프로젝트 성과를 향상시키기 위한 노력을 하고 있다. SW 개발 프로젝트의 성과 는 $\mathrm{SW}$ 개발 과정에서 달성되는 성과와 $\mathrm{SW}$ 제품에 대한 품질 성과로 구성된다. SW 개발 프로젝트의 성과를 극대화하기 위해서는 SW 개발자들이 체계 적으로 개발을 수행할 수 있을 뿐만 아니라 개발 과정을 효율적으로 관리하기 위한 프로세스가 잘 정립되어 있어야 한다. 또한 잘 정립된 프로세스 에 따라 작업을 수행할 수 있는 개발자 인력과 이 들이 활용할 수 있는 좋은 기술과 시스템이 갖추 어져야 한다.

성공적인 $\mathrm{SW}$ 개발 프로젝트의 수행을 위해 필 요한 SW 개발 프로세스, 인력 및 시스템 인프라 가 잘 갖추어져 있는지를 측정하기 위해 $\mathrm{SW}$ 공학 수준(SEL : Software Engineering Level)조사 도 구를 개발하고, 이를 기반으로 국내 $\mathrm{SW}$ 기업들의 $\mathrm{SW}$ 공학수준조사를 진행하였다.

$\mathrm{SW}$ 공학수준을 측정하기 위한 지표들은 기본 적으로 미국 SEI(Software Engineering Institute) 에서 개발한 CMMI(Capability Maturity Model Integration) V1.2를 기반으로 개발되었다. 특히, 프 로세스 영역의 지표들은 CMMI 모델의 레벨 2와 레벨 3의 18개 주요 프로세스 영역(Key Process Area : KPA)을 바탕으로 개발되었고, 참조한 18 개 주요 프로세스 영역들은 <표 1>과 같다.

$\mathrm{SW}$ 공학수준의 측정은 $\mathrm{SW}$ 개발에 대한 업무

〈표 1〉 CMMI 레벨 2와 3의 주요 프로세스 영역

\begin{tabular}{|c|c|c|c|c|}
\hline & Project Management & Engineering & Support & Process Management \\
\hline level 2 & $\begin{array}{l}\text { 。 프로젝트 계획수립 } \\
\text { 。프로젝트 모니터링 및 } \\
\text { 통제 } \\
\text { 。공급업체 관리 }\end{array}$ & - 요구사항 관리 & $\begin{array}{l}\text { 。 형상 관리 } \\
\text { 。프로세스 및 제품품질 } \\
\text { 보증 } \\
\text { 。측정 및 분석 }\end{array}$ & 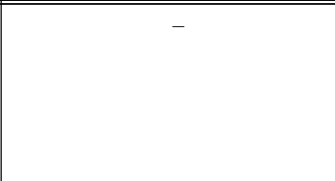 \\
\hline level 3 & $\begin{array}{l}\text { ○ 통합 프로젝트 관리 } \\
\text { • 위험관리 }\end{array}$ & $\begin{array}{l}\text { 。 요구사항 개발 } \\
\text { 。 기술적 해결 } \\
\text { 。 제품 통합 } \\
\text { 。 검증 } \\
\text { 。 확인 }\end{array}$ & 。 의사결정 분석 및 해결 & \begin{tabular}{|l} 
。 조직 프로세스 정의 \\
。 조직 프로세스 중점관리 \\
。 조직 교육관리
\end{tabular} \\
\hline
\end{tabular}


표준인 프로세스(Process), SW 개발을 수행하는 인력 및 조직을 의미하는 인력(People), SW 개발 시 적용되는 기술 및 시스템 인프라를 의미하는 기술(Technology) 등의 3가지 핵심영역에 대해 개 발된 지표를 통해 측정되었다(<표 2> 참조).

〈표 2〉SW 공학수준조사 지표의 구성

\begin{tabular}{|c|c|}
\hline 구 분 & 지표 측정의 주요내용 \\
\hline $\begin{array}{l}\text { 프로세스 } \\
\text { (Process) } \\
\text { 영역 }\end{array}$ & $\begin{array}{l}\text { 프로젝트 관리, 개발, 지원, 프로세스 } \\
\text { 관리 등 성공적 소프트웨어 개발을 위한 } \\
\text { 프로세스 이행 및 내재화 정도를 } \\
\text { 확인하기 위한 지표 }\end{array}$ \\
\hline $\begin{array}{l}\text { 인력 } \\
\text { (People) } \\
\text { 영역 }\end{array}$ & $\begin{array}{l}\text { 전문 지원조직 체계, 사내 전문가 보유, } \\
\text { 조직원 역량강화 등 조직 인력 운영 } \\
\text { 체계를 갖추고 있는지를 확인하기 위한 } \\
\text { 지표 }\end{array}$ \\
\hline $\begin{array}{c}\text { 기술 } \\
\text { (Technology) } \\
\text { 영역 }\end{array}$ & $\begin{array}{l}\text { 시스템 인프라 구성, SW 개발 표준 및 } \\
\text { 기법 보유, 정보관리 체계 등 프로세스 } \\
\text { 체계가 구성, 활용되고 있는지를 } \\
\text { 확인하기 위한 지표 }\end{array}$ \\
\hline
\end{tabular}

프로세스, 인력, 기술 영역에 대한 SW 공학수준 측정 결과에 대한 점수화는 $\mathrm{CMMI}$ 의 공식심사 기 법인 SCAMPI(Standard CMMI Appraisal Method for Process Improvement) 방식을 벤치마킹하였 다. 각각의 프로세스 영역은 프로세스 개선활동에 중요한 목표 $(\mathrm{Goal})$ 들과 이를 달성하기 위해 수행 되어야 하는 활동(Practice)들의 모음이다. 프로세 스 영역은 목표와 활동으로 구성되며, 목표는 모 든 프로세스 영역에서 공통적으로 충족되어야 하는 공통 목표(Generic Goal)와 특정 프로세스 영역에 서 만족되어야 하는 고유 목표(Specific Goal)로 구성되고, 각 목표를 달성하기 위해 필요한 활동들 은 공통 활동(Generic Practice)과 고유 활동( $\mathrm{Spe}^{-}$ cific Practice)으로 구성된다([그림 1] 참조).

고유 활동은 해당 프로세스에 부여된 고유 목표 를 달성하기 위해 기대되는 활동들을 의미한다. 공 통 활동은 공통 목표의 달성과 고유 활동들이 일 회성으로 유지되는 것이 아니라 조직 내에 내재화 되어 지속적으로 수행될 수 있도록 기대되는 활동 들이다.
프로세스 영역의 활동에 대한 측정 점수는 해당 프로세스 영역의 목적을 달성하기 위해 필요한 공 통 활동과 고유 활동을 이행하고 있는지를 2점 척 도(수행/미수행)로 이행하면 1점 아니면 0점을 부 여하였다. 인력이나 기술 영역도 동일한 방법을 적용하여 해당 업무를 수행하는 인력이나 기술이 존재하는 경우는 1 점을 없는 경우는 0 점을 부여하 였다.

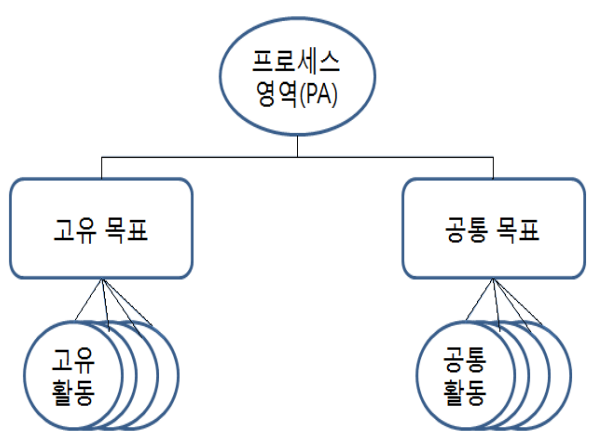

[그림 1] 프로세스 영역의 구성

$\mathrm{SW}$ 공학수준 지표 각각에 점수를 부여하고 세 가 지 주요 영역에 가중치를 부여하여 100점 만점으 로 SW 공학수준 점수를 산출하였다. 산출된 점수 를 바탕으로 Advanced, Average, Absent의 3가지 등급으로 $\mathrm{SW}$ 공학수준을 분류하였고, 등급별 $\mathrm{SW}$ 기업 및 조직의 특성을 설명하였다(<표 $3>$ 참조).

\subsection{SW 프로세스 적용 및 개선 사례}

$\mathrm{SW}$ 개발 프로젝트의 일반적인 목표는 최소 일 정과 비용을 투입하여 최상의 품질과 최대의 고객 만족을 얻는 것이다. 이러한 SW 프로젝트의 성공 은 최신 기술이나 기법, 전문적인 조직이나 인력, 기반 시스템 및 도구의 활용 등 여러 요소들에 영 향을 받으며, 프로젝트의 규모, 특성, 상황 등에 따 라 적절하게 $\mathrm{SW}$ 프로젝트의 성공 목표가 설정되 어야 바람직하다. 또한, $\mathrm{SW}$ 프로젝트 수명주기상 경영자, 발주자, 개발자, 관리자 등 여러 계층별로 관심사는 서로 다르기 때문에 $\mathrm{SW}$ 프로젝트의 성 공기준 또한 서로 다르며 모두를 만족시키는 것은 
〈표 3〉 소프트웨어공학수준 등급별 특성

\begin{tabular}{|c|c|c|}
\hline 등급 & 점수 & 등급별 소프트웨어기업 특성 \\
\hline Advanced & \begin{tabular}{|l} 
80점 \\
이상
\end{tabular} & $\begin{array}{l}\text { 프로젝트 관리, 개발, 지원, 프로 } \\
\text { 세스 관리 활동이 균형을 이루며 } \\
\text { 실제 업무 환경에 잘 적용되어 그 } \\
\text { 효과가 충분히 발생되고 있으며, } \\
\text { 해당 활동들의 내재화가 조직 내에 } \\
\text { 서 충분히 이루어지고 있는 조직 }\end{array}$ \\
\hline Average & $\begin{array}{c}\text { 60점 } \\
\text { 이상 } \\
\text { 80점 } \\
\text { 미만 }\end{array}$ & $\begin{array}{l}\text { 프로젝트 관리, 개발, 지원, 프로세 } \\
\text { 스 관리 환동의 일부만이 실제 업무 } \\
\text { 환경에 적용되어 일부의 효과가 발 } \\
\text { 생되고 있으며, 해당 활동들의 내재 } \\
\text { 화가 일부 수행되고 있는 조직으로 } \\
\text { 지속적인 프로세스 개선 및 내재화 } \\
\text { 노력이 필요한 조직 }\end{array}$ \\
\hline Absent & $\begin{array}{l}\text { 60점 } \\
\text { 미만 }\end{array}$ & $\begin{array}{l}\text { 프로젝트 관리, 개발, 지원, 프로세 } \\
\text { 스 관리 활동의 대부분이 실제 업무 } \\
\text { 환경에 적용되지 못하고 있으며, } \\
\text { 해당 활동들의 내재화 또한 수행되 } \\
\text { 고 있지 않은 조직으로 프로세스 및 } \\
\text { 내재화에 대한 인식 전환이 시급한 } \\
\text { 조직 }\end{array}$ \\
\hline
\end{tabular}

쉽지 않은 일이다[2].

$\mathrm{SW}$ 프로세스는 고품질 SW를 개발하기 위해 필 요한 SW 수명주기 상의 핵심적인 활동들을 제시 하고 있는 작업체계를 의미한다. 따라서 보다 체계 적이고 성숙된 SW 프로세스 역량은 보다 높은 품 질의 $\mathrm{SW}$ 제품 생산이 가능할 것이라는 것이 $\mathrm{SW}$ 프로세스의 기본 개념이다. 이미 많은 SW 개발 조직들은 $\mathrm{SW}$ 프로세스 역량 개선이 $\mathrm{SW}$ 프로젝 트 성과 및 $\mathrm{SW}$ 제품의 품질향상으로 이어진다고 알고 있다.

대표적인 $\mathrm{SW}$ 프로세스 개선 모델인 $\mathrm{CMM}$ 는 미국 국방성 의뢰를 받아 카네기멜론대학 SW 공 학연구소에서 개발한 정보기술 조직의 프로세스 전반을 종합적으로 평가하기 위한 성숙도 모델로, 많은 SW 관련 조직들은 프로세스 개선을 통해 비 용, 납기, 품질, 고객만족도 등과 같은 성과를 효율 적으로 달성하기 위해 이를 적용 및 도입하고 있 다. 실제로 $\mathrm{CMM}$ 를 통한 $\mathrm{SW}$ 기업들의 프로세스 적용과 개선 효과에 대해 살펴보면 결함수정 비용 이 평균 $33 \%$ 감소되어 전체 프로젝트 비용을 절
감하는 효과가 있었고, 테스트 이후 재작업이 $60 \%$ 감소되어 프로젝트 전체 일정을 단축하는 효과가 있었다. 또한 고객 만족도는 평균 $14 \%$, 품질 향상 률은 평균 $48 \%$ 향상되었다고 한다[4].

\section{3. 연구 모델 및 연구가설}

\section{1 연구 모델}

$\mathrm{CMMI}$ 를 포함한 프로세스 개선 모델들이 가지 는 기본적인 가정사항(Proposition)은 조직의 프로 세스 능력수준이 높으면 보다 좋은 $\mathrm{SW}$ 프로젝트 성과나 생산성으로 이어진다는 것이다. 본 연구에 사용되고 있는 $\mathrm{SW}$ 공학수준 지표들은 $\mathrm{CMMI}$ 를 기반으로 작성되었고, $\mathrm{CMM}$ 의 공식 심사등급 체 계와는 다른 등급체계를 가지고 있지만 기본적으 로 동일한 기능을 수행하고 있다. 즉, $\mathrm{SW}$ 개발기 업의 $\mathrm{SW}$ 개발 능력수준을 측정하는데 이를 활용 할 수 있다. 따라서 $\mathrm{CMMI}$ 모델의 가정사항과 동 일하게 SW 공학수준이 높으면 SW 프로젝트 성 과가 높을 것이라는 가정을 담고 있다. 이를 기반 으로 연구모델을 작성하면, [그림 2]와 같다. $\mathrm{SW}$ 공학수준에 따라 $\mathrm{SW}$ 관련 조직의 성과가 달라지 고, 조직의 규모에 따라서도 성과가 달라질 수 있 다는 것을 연구하고자 한다.

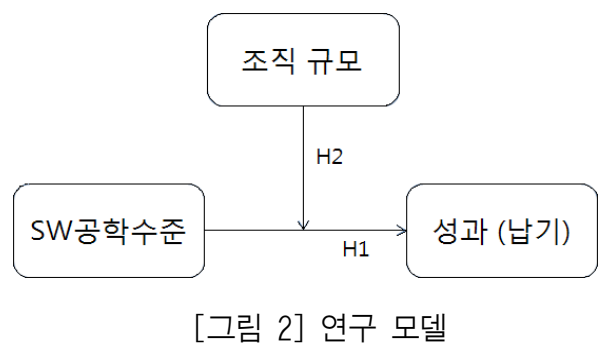

\section{2 연구가설}

\subsection{1 프로세스 성숙도와 납기편차율}

많은 프로세스 전문가들은 조직의 높은 $\mathrm{SW}$ 프 로세스 성숙도 수준이 조직적 및 경제적인 이익을 
준다고 주장한다 [6, 15]. 소프트웨어 개발과정 중 결함율 감소, 소프트웨어 개발 완료 후 결함 감소, 소프트웨어 프로젝트 납기 준수 그리고 개발, 테 스팅, 유지보수 비용의 절감 등과 같은 많은 이익 을 주고 있음이 여러 사례를 통해 확인되었다.

Goldeson and Herbsleb[5]의 2003년 보고서는 $\mathrm{CMMI}$ 적용을 통한 프로세스 개선 결과에 대한 영 향력 및 이점에 대한 실증적 결과를 소개하였다. 정 보기술, 금융, 자동차, 항공, 교육 등 다양한 분야에 서 소프트웨어 시스템을 개발, 통합, 관리하는 과 정에 $\mathrm{CMMI}$ 를 적용하여 프로세스 개선활동을 진 행한 미국와 유럽에 있는 11 개 조직의 12 개 사례 로부터 수집된 성과를 비용, 일정, 품질, 고객만족 도, 투자대비 이익 이라는 5가지 측면에서 나타내 었다. 작업을 완료하는데 필요한 일정을 감축하거 나 정해진 일정 내에 작업을 완료하는 것에 대한 예측가능성과 같은 일정관련 이익 및 효과를 제공 하였음을 소개하였다. 일정을 단축하거나 일정 지 연일수를 단축하여 결과적으로 생산성이 향상되었 음이 General Motors, Boeing, Lockheed Martin, JP Morgan 등의 사례를 통해 높은 프로세스 역량 수준에 대한 이점이 실증적으로 확인되었다.

〈표 4〉 $\mathrm{CMMI}$ 적용 성과분석 결과

\begin{tabular}{c|c|c|c}
\hline 성과 & $\begin{array}{c}\text { 중위 그룹 } \\
\text { (median) }\end{array}$ & $\begin{array}{c}\text { 하위 그룹 } \\
\text { (Lowest) }\end{array}$ & $\begin{array}{c}\text { 상위 그룹 } \\
\text { (Highest) }\end{array}$ \\
\hline \hline 비용 & $34 \%$ & $3 \%$ & $87 \%$ \\
\hline 납기 & $50 \%$ & $2 \%$ & $95 \%$ \\
\hline 생산성 & $61 \%$ & $11 \%$ & $329 \%$ \\
\hline 품질 & $48 \%$ & $2 \%$ & $132 \%$ \\
\hline 고객 만족도 & $14 \%$ & $-4 \%$ & $55 \%$ \\
\hline 투자대비 수익 & $4: 1$ & $1.7: 1$ & $22.7: 1$ \\
\hline
\end{tabular}

Gibson et al.[7]은 CMMI를 기반으로 프로세스 개선을 추진한 35 개 조직들을 대상으로 조사한 성 과를 비용, 스케줄, 생산성, 품질, 고객만족도 및 투 자수익율과 같은 6 가지 측면에서 분석하였다 $(<$ 표 $4>$ 참조). 분석결과는 개선의 정도를 기반으로 상/ 중/하위 그룹으로 구분하였고, 전반적으로 $\mathrm{CMMI}$
를 통한 프로세스 개선의 영향이 긍정적으로 나타 나고 있음이 확인되었다. 특히, 납기분야를 살펴보 면 최저 $2 \%$ 수준까지 최고 $95 \%$ 까지 개선되고 있 음을 알 수 있다. 이와 같은 선행연구를 기반으로 설정된 가설 1 은 다음과 같다.

가설 $1: \mathrm{SW}$ 공학수준이 높을수록 $\mathrm{SW}$ 프로젝트 납기 편차율은 줄어들 것이다(H1).

\subsection{2 조직 규모의 효과}

조직의 규모는 SW 프로세스 연구에서 가장 많이 다루어지는 조절변수중의 하나이다 $[5,8]$. 하지만, 조직 규모의 효과에 대한 결과는 서로 상반되는 결과를 보이고 있다. 즉, 조직 규모가 조절변수의 역할을 수행하거나 혹은 조절변수가 아니라 독립 변수의 역할을 수행하는 것으로 분석되기도 한다.

SW-CMM 기반의 Brodman[8]의 연구에 따르면, $\mathrm{SW}$ 프로세스를 개선하기 위한 인력과 자금이 부 족한 작은 조직은 일부 활동에서 규모가 큰 조직에 비해 비용대비 효과가 떨어지는 것으로 제시되고 있다. ISO/IEC 15504(SPICE) Phase 2 Trials[9, 10]을 기반으로 한 연구에서는 일부 프로세스에서 능력수준과 성과의 관계가 규모가 큰 조직에서 강 하게 나타는 것으로 제시되고 있다.

반면에, SW-CMM 기반의 다른 연구 $[5,11]$ 에 따르면, 조직 규모는 조직의 성숙도나 조직의 성 과와 관련이 없는 것으로 제시되고 있다. 규모가 작은 조직의 $\mathrm{SW}$ 엔지니어들이 조직의 높은 역량 수준에서 얻는 혜택은 큰 조직의 혜택과 동일한 것으로 제시되고 있다. 이러한 결과는 조직의 역 량수준과 프로세스 성과 사이의 관계와 동일하게 나타나고 있다. 이러한 기존 연구결과를 바탕으로 조직 규모와 성과에 대한 연구가설을 다음과 같이 설정하였다

가설 $2: \mathrm{SW}$ 공학수준과 $\mathrm{SW}$ 프로젝트 성과인 납 기의 관계는 기업 규모에 따라 다르게 나 타날 것이다(H2). 


\section{4. 데이터 수집 및 측정지표}

\section{1 데이터 수집}

본 연구에 사용된 데이터는 정보통신산업진흥원 의 SW 공학센터에 수행되는 SW 공학수준조사를 통 해 수집되었다. 조사기간은 2010년 9월부터 11월 까지 약 3 개월에 걸쳐 수집되었다. 분석에 사용된 자료는 총 121 개 프로젝트의 데이터가 활용되었다.

설문 조사 및 분석 대상은 $\mathrm{SW}$ 개발 프로젝트이 고, 설문 응답자는 해당 프로젝트를 수행하는 프로 젝트 관리자(Project Manager)나 프로젝트 리더 (Project Leader)들로 구성되었다. SW 개발 프로 젝트는 IT서비스, 패키지 SW 및 임베디드 $\mathrm{SW}$ 개 발 프로젝트가 주류를 이루고 있다.

\subsection{SW 공학수준 측정지표}

\subsection{1 프로세스 수준 지표}

프로세스 수준 지표는 SW 개발 수행 시 조직 차 원에서 필요한 활동들의 이행 수준과 원활한 이행 을 위하여 필요한 내재화 수준을 확인하기 위한 하 위 지표들로 구성되었다. 프로세스 이행수준 지표 는 SW 개발 시 조직 차원에서 필요한 활동들을 실 제로 수행하고 있는지를 확인하기 위한 측정 지표 들로 구성되며, 프로세스 내재화수준 지표는 수행 되어야 할 활동들이 일회성 아니라 필요한 활동들 을 지속적으로 수행될 수 있도록 공식적인 규정이 나 조직이 존재하고, 필요한 인력이나 예산이 지 원되는지를 확인하기 위한 측정 지표들로 구성되 었다.

프로세스 수준 측정 지표는 18 개 프로세스 영역 에 대해 총 145 개의 문항으로 작성하였다. 이중에 서 프로젝트 계획(Project Planing)의 측정 내용을 살펴보면 다음과 같다(<표 5> 참조).

\subsection{2 인력 수준 지표}

인력 수준 지표는 SW 개발 조직이 개발을 효율
〈표 5〉 프로젝트 계획 프로세스의 측정내용

\begin{tabular}{|c|c|}
\hline 구 분 & 측정 내용 \\
\hline $\begin{array}{l}\text { 프로 } \\
\text { 젝트 } \\
\text { 계획 }\end{array}$ & $\begin{array}{l}\text { 프로젝트 범위 견적 이행여부 } \\
\circ \text { 작업산출물 및 작업 속성 견적 이행여부 } \\
\circ \text { 프로젝트 개발방법론 정의 여부 } \\
\circ \text { 노력 및 비용 견적 이행여부 } \\
\circ \text { 예산 및 일정수립 이행여부 } \\
\circ \text { 프로젝트 위험요소 식별 이행여부 } \\
\circ \text { 데이터 관리 계획수립 이행여부 } \\
\circ \text { 프로젝트자원 계획수립 이행여부 } \\
\circ \text { 필요지식 및 기술 확보 계획수립 이행여부 } \\
\circ \text { 관련 이해관계자 참여계획 수립 이행여부 } \\
\circ \text { 프로젝트 계획수립 이행여부 } \\
\circ \text { 프로젝트에 영향을 주는 타 계획 검토 } \\
\text { 이행여부 옥 섭 및 자원 수준조정 이행여부 } \\
\circ \text { 계획에 대한 공동합의 확보 여부 }\end{array}$ \\
\hline
\end{tabular}

적으로 수행하도록 지원조직과 역할체계가 잘 구 성되고, 개발자들의 역량을 향상시키기 위한 교육 등이 적절히 수행되고 있는지를 확인하는 지표들 로 구성되었다. 이를 위해 전문 지원조직 체계, 사 내 전문가 보유, 프로젝트 수행 역할체계, 조직원 역량강화, 조직 인력운영 등 5 개의 영역에 걸쳐 71 개 세부 측정항목으로 구성되었다([그림 3] 참조).

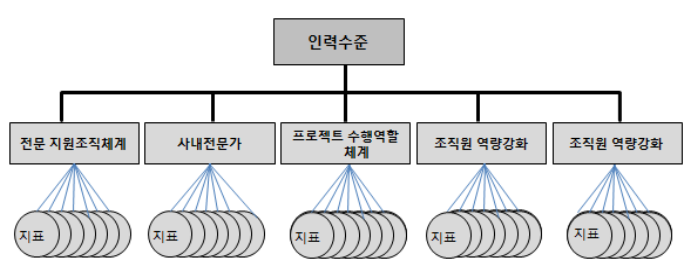

[그림 3] 인력수준 지표의 구성

인력 수준 지표 중 전문 지원조직체계의 세부 측 정항목은 총 9 개의 세부 측정항목으로 주로 $\mathrm{SW}$ 개발 프로젝트의 품질관리를 위한 전문조직이나 인력들이 잘 갖추어져 있는지를 측정하는 항목으 로 구성되어 있다(<표 6> 참조).

\subsection{3 기술 수준 지표}

기술 수준 지표는 SW 개발 기업의 조직원들이 $\mathrm{SW}$ 개발을 제대로 수행하기 위하여 필요한 시스 
〈표 6〉전문 지원조직체계의 측정내용

\begin{tabular}{|c|c|}
\hline 구 분 & 측정 내용 \\
\hline $\begin{array}{l}\text { 전문 } \\
\text { 지원 } \\
\text { 조직 } \\
\text { 체계 }\end{array}$ & 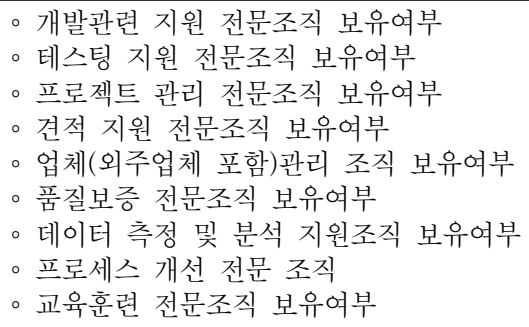 \\
\hline
\end{tabular}

템적인 인프라가 적절하게 구축되었는지를 측정하 기 위한 지표들로 구성되었다. SW 개발 조직의 시스템 인프라구축 수준을 측정하기 위해 프로세 스 인프라, 시스템의 인프라, 개발표준 및 기법 및 정보활용 등을 포함한 4 개 영역에 걸쳐 총 42 개의 세부 측정항목들로 구성되었다([그림 4] 참조).

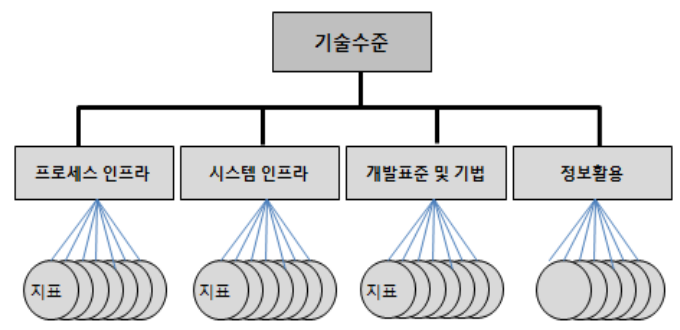

[그림 4] 기술수준 지표의 구성

기술수준의 측정항목 중에서 시스템 인프라의 측정항목을 구체적으로 살펴보면 '조직 표준 프로 세스 및 산출물의 통합 시스템 보여 여부를 포함 한 7 개의 하위측정지표로 구성되었다. 시스템 인 프라 영역은 주로 조직의 표준 프로세스 자산을 통합적으로 관리할 수 있는 시스템이나 프로젝트 관리와 관련 시스템이나 도구들이 구비되었는지를 측정하는 항목으로 구성되었다(<표 7> 참조).

\subsection{4 납기 편차율}

$\mathrm{SW}$ 개발 프로젝트 성과를 측정하는 종속변수로 납기편차율 변수를 사용하였다. 납기편차율은 프 로젝트 계획 수립 시 설정된 납기일정과 실제 프로
〈표 7〉시스템 인프라의 측정내용

\begin{tabular}{|c|c|}
\hline 구 분 & 측정 내용 \\
\hline $\begin{array}{l}\text { 시스템 } \\
\text { 인프라 }\end{array}$ & $\begin{array}{l}\text { 조직 표준 프로세스 및 산출물의 통합 } \\
\text { 시스템 보유 여부 } \\
\text { 。프로젝트 관리 시스템 보유여부 } \\
\text { 옹수 수집관리 시스템 보유여부 } \\
\text { 。형상관리 툴 및 시스템 보유여부 } \\
\text { 모델링 전용툴 보유여부 } \\
\text { ○요구사항 관리툴 보유여부 } \\
\text { 。테스팅 관련 시스템 보유여부 }\end{array}$ \\
\hline
\end{tabular}

젝트 종료에 들어간 기간과의 차이에 대한 절대값 으로, 이를 기준으로 납기준수 여부를 파악하였다.

납기를 준수했다는 것은 납기편차율 값이 0이거 나 혹은 0 보다 작다는 것을 의미한다. 납기 편차율 이 0보다 작은 프로젝트의 수가 많지 않았기 때문 에 이들은 납기를 준수한 프로젝트로 분류하여 분 석하였다.

\section{5. 분석방법 및 결과}

\section{1 음이항 회귀분석}

납기 편차율에 대한 변수 설명에서 언급한 것처 럼 본 연구의 종속변수인 프로젝트의 납기준수율 값을 음의 정수가 아닌 절대값으로 정의하였다. 이 러한 자료의 특성 때문에 상관관계 분석보다는 회 귀분석을 실시였다. 특히 기업의 규모와 조절변수 가 포함된 모델의 분석에는 회귀분석이 적절한 분 석으로 제시되고 있다[12].

여러가지 회귀분석 중에서 $\mathrm{SW}$ 공학수준과의 관 계를 살펴보기 위해 음이항 회귀분석(negative binomial regression) 분석을 실시하였다. 음이항 회 귀분석은 포아송 회귀분석의 확장모델으로 일반회 귀분석의 가정사항인 동분산성을 만족하지 못하거 나, 포아송 회귀분석의 가정사항인 분산과 평균이 같지 않고 분산이 평균보다 큰 과분산(overdispersion)일 경우에 활용된다[13].

음이항 분포는 납기준수율 $\left(\lambda_{i}\right)$ 항에 오차항 $\left(\varepsilon_{i}\right)$ 이 포함되며 이를 수식으로 표현하면 다음과 같다. 


$$
\lambda_{i}=\exp \left(\beta_{0}+\beta X_{i}+\varepsilon_{i}\right)
$$

단, $\exp \left(\varepsilon_{i}\right)$ 는 오차항으로 평균이 1 이고, 분산이 $\alpha$ 인 감마분포로 가정한다.

\section{2 모델 안정성}

흔히 민감도(sensitivity)로 언급되는 모델의 안 정성은 이상치 데이터에 영향을 받는 정도를 의미 한다. 모델의 안정성은 수집된 데이터의 일부를 활 용하여 산출된 모델의 변수상에 일어나는 변화를 측정하여 평가된다[22]. 무작위 샘플을 통해 수집 되지 않은 데이터의 분석결과는 모델의 안정성이 보장되어야 한다[23, 24].

본 연구에서는 모델의 안정성은 붓스트랩 기법 을 활용하였으며, 복원 추출횟수는 1,000 번 실시하 여 분석하였다[14]. 수집자료의 분석을 통해 산출 된 통계 값들이 복원 추출을 통해 산출된 경험적 신뢰구간의 중앙에 위치하면 안정적인 것으로 분 류된다. 즉, 경험적 신뢰구간의 상/하위 경계에 존 재하지 않아야 한다는 것을 의미한다. 이러한 안 정성 편향(stability bias)을 평가하는 식은 다음과 같다.

$$
\text { Bias }=\frac{\sum_{b=1}^{B} t_{b}^{*}}{B}-\hat{\theta}
$$

$t_{b}^{*}$ 는 $\mathrm{b}$ 번째 샘플의 통계 값이고, $\mathrm{b}$ 는 $1, \cdots, \mathrm{B}$ 를, $\hat{\theta}$ 는 원 수집자료에서 분석된 통계 값을 의미한다. 편향의 정도는 $\mathrm{B}$ 번의 반복을 통해 나온 분포의 표 준오차(standard error)를 기반으로 평가되며, 이 때 표준오차는 다음과 같이 계산된다.

$$
S E=\sqrt{\frac{\sum_{b=1}^{B}\left(t_{b}^{*}-\overline{\left.t^{*}\right)}\right.}{B-1}} \text { 단, } \bar{t}^{*}=\sum_{b=1}^{B} t_{b}^{*} / B
$$

만약 편향(bias)이 표준오차에 비해 크다면, 안
정성에 문제가 있는 것이다. 안정성을 판단하는 기 준(criteria)은 편향의 절대값이 표준오차의 $1 / 4$ 보 다 적다면 편향은 무시될 수 있다[16].

붓스트랩 방법론은 실증적 소프트웨어공학연구 에서 이전부터 활용되어온 분석방법이다. El-Emam 과 Garro[17]는 포획/재포획(capture-recapture)방 법을 활용하여 ISO/IEC 15504심사 횟수를 추정하 였다. Jung and Hunter[18]는 개별 ISO/IEC 15504 프로세스의 능력 수준(capability level)의 신뢰구간 을 계산하는데 붓스트랩을 활용하였으며, Jung and Goldenson[19]은 SW-CMM의 내적 일관성(Internal consistency)에 대한 안정성을 평가하기 위해 붓스트랩을 활용하였다.

\section{3 기술통계 분석}

분석대상 프로젝트 중에서 SW 공학수준의 분포 를 살펴보면, Advanced 등급이 28\%(34/121), Average 등급이 46\%(56/121), Absent 등급의 프로젝 트가 25\%(31/121)인 것으로 나타났다. 또한 121 개 프로젝트 중에서 33개 프로젝트에서 납기지연이 발생한 것으로 분석되고 있다(<표 8> 참조).

〈표 8〉 분석대상 프로젝트 정보

\begin{tabular}{c|c|c|c}
\hline & Absent & Average & Advanced \\
\hline \hline 프로젝트 수 & 34 & 56 & 31 \\
\hline $\begin{array}{c}\text { 납기지연 } \\
\text { 프로젝트 수 }\end{array}$ & 21 & 8 & 4 \\
\hline
\end{tabular}

아래의 그림은 SW 공학수준별 납기 편차율의 평균과 분산을 나타내고 있다. 분석결과를 살펴보 면 SW 공학수준이 높을수록 납기편차율의 평균 과 분산 값이 줄어드는 것을 알 수 있다. 이는 $\mathrm{SW}$ 공학수준이 높을수록 납기편차가 줄어들어 $\mathrm{SW}$ 개발 프로젝트의 성공 확률이 높아지고, 분산이 줄어들어 프로젝트의 예측가능성이 높아지는 것을 알 수 있다([그림 5], [그림 6] 참조). 


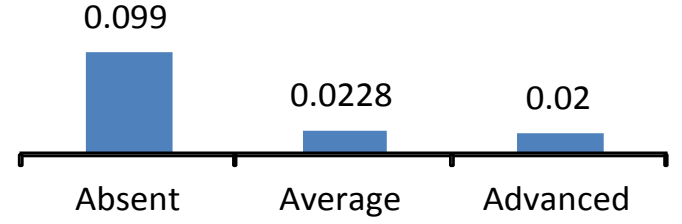

[그림 5] SW 공학수준별 납기편차율 평균

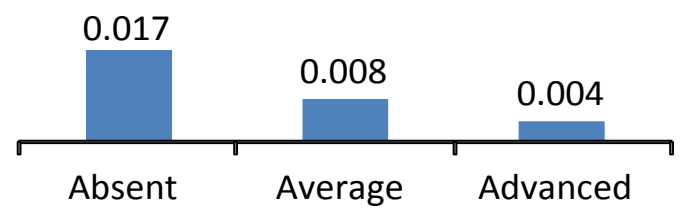

[그림 6] SW 공학수준별 납기편차율 분산

\section{4 분석결과}

\subsection{1 상관관계 분석}

음이향 회귀분석에 앞서 변수들 간의 관계에 대 한 사전정보를 얻고, 다중공선성 위험을 식별하기 위해 피어슨 상관관계 분석을 실시하였다. 상관관 계 분석결과를 살펴보면 $\mathrm{SW}$ 공학수준(SEL)과 납 기준수율 $(\mathrm{SCH})$ 과의 상관계수가 -0.359 으로 이들 간에 음의 상관관계가 있음을 알 수 있다 $(<$ 표 9> 참조),

〈표 9〉 상관관계 분석결과

\begin{tabular}{c|c|c|c}
\hline & SCH & SEL & SEL $\times$ SIZE \\
\hline \hline SCH & & $-0.359^{*}$ & $-0.263^{*}$ \\
\hline SEL & & & $0.688^{*}$ \\
\hline SEL $\times$ SIZE & & & \\
\hline
\end{tabular}

주) ${ }^{*}$ 유의수준 $<0.05, \mathrm{SCH}$ : 납기편차율, $\mathrm{SEL}: \mathrm{SW}$ 공학수준.

\section{4 .2 회귀분석결과}

기업규모에 따른 SW 공학수준과 납기준수율과 의 음이항 회귀분석 결과는 다음과 같다.

$$
\begin{aligned}
\overline{\hat{\mu}}= & \exp \left(0.121_{(<0.813)}-0.766_{\left(<0.034^{*}\right)}\right. \text { 공학수준 } \\
& \left.-0.098_{(<0.677)} \text { 공학수준 } \times \text { 기업규모 }\right)
\end{aligned}
$$

분석결과를 살펴보면, $\mathrm{SW}$ 공학수준의 회귀계수 가 -0.766 으로 유의 0.05 수준에서 통계적으로 유의 한 것으로 분석되었다. 이는 앞서 상관관계 분석 에서 예측된 것처럼 $\mathrm{SW}$ 공학수준이 한 단위 높아 질수록 납기편차율이 0.766 만큼 줄어다는 것을 의 미한다. 즉, SW 공학수준이 높을수록 납기편차율 이 낮아진다는 것을 의미한다.

하지만 기업의 규모는 납기편차율에 영향을 미치 지 않는 것으로 나타났다. 이런 현상은 $\mathrm{CMM}$ 에서 정의하고 있는 주요 프로세스 영역의 활동을 성실 하게 수행할 경우, 기업의 규모에 상관없이 $\mathrm{SW}$ 공학수준에 따른 효과는 유사한 것으로 나타났다.

1,000 번의 표본 추출을 통한 붓스트랩 결과 분 석을 살펴보면, $\mathrm{SW}$ 공학수준의 추정된 회귀계수 의 편차가 0.071 로 표준오차 0.409 의 $1 / 4$ 보다 적게 나타나고 있다([그림 7] 참조). 따라서 최종 회귀 모델은 안정적이라 것을 알 수 있다. 또한, $\mathrm{SW}$ 공 학수준에 대한 붓스트랩 분석의 $95 \%$ 신뢰구간을 살펴보면 -1.539 에서 -0.103 으로 나타나고 있다. 이는 SW 공학수준 납기편차율에 영향을 미친다는 가설이 유의수준 0.05 수준에서 통계적으로 유의하 다는 것을 보여주고 있다.

모델의 적합성은 유사 $\mathrm{R} 2$ 값을 기준으로 평가하 였다. 종속변수의 변동을 회귀모형이 얼마나 잘 반 영하는가를 나타내는 모델의 설명력은 우연히 발생

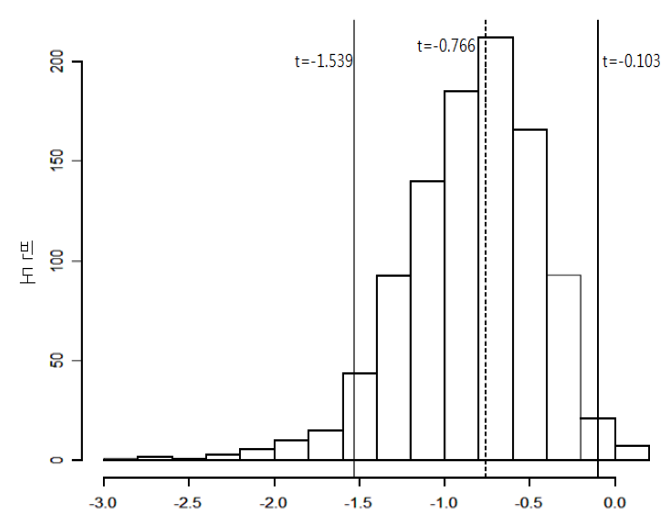

[그림 7] 붓스트랩 $\mathrm{t}$ 값의 분포(복원 추출 1000회) 
할 확률을 평가하는 유의수준 테스트와는 다르다.

Cohen[16]은 이런 모델의 설명력(R2)을 소(0.0196) /중(0.13)/대(0.26)로 분류하였다. Cohen의 분류기준 에 따르면 본연구의 유사 $\mathrm{R} 2$ 값 0.14 는 중간정도 의 설명력을 가지는 것으로 분석되었다.

\section{6. 결론 및 한계점}

IT 융-복합화가 가속화되면서, 기존 제품의 부 가가치 및 경쟁력을 높이는데 중요한 역할을 수행 하는 SW 품질을 높이기 위해 SW 개발 기업들은 자신들의 $\mathrm{SW}$ 공학수준을 높이기 위해 많은 노력 을 기울이고 있다.

본 연구는 이러한 노력들이 SW 프로젝트 성과 와 연결되고 있는지를 살펴보기 위해 SW 공학수 준에 따라 납기편차율이 줄어지는지와 기업의 규 모에 따라 성과가 달라지는지를 통계적 모형을 통 해 검증하였다. 연구결과를 간단하게 요약하면 다 음과 같다.

첫째, SW 공학수준이 높을수록 $\mathrm{SW}$ 개발 프로 젝트의 납기편차율이 줄어드는 것으로 분석되었다. 이는 $\mathrm{CMMI}$ 를 포함한 일반적인 프로세스 개선 모 형들이 가지고 있는 전제조건인 SW 개발 프로세스 가 개선되면, $\mathrm{SW}$ 제품의 품질을 포함한 성과가 좋 아진다는 것을 실증적으로 보여주고 있다. 또한 개 별기업들의 SW 공학역량을 높이기 위한 노력을 기 울여야하는 타당성의 근거를 제시하는 결과이다.

둘째, 기업의 규모에 따른 SW 공학수준의 효과 는 차이가 없는 것으로 나타났다. 이는 $\mathrm{CMM}$ 에서 제시하는 주요 프로세스 영역의 활동을 충실하게 수 행할 경우 유사한 효과가 나타나는 것으로 보인다. 이런 현상이 발생하는 요인 중의 하나로는 현재 분 석대상이 프로젝트를 수행한 전체 조직의 $\mathrm{SW}$ 공 학역량수준이 아니라 설문에 응답한 하나의 프로 젝트만을 대상으로 분석이 수행되었기 때문에 기 업 규모의 차이에 대한 효과가 나타나지 않은 것 으로 보인다.
본 연구의 $\mathrm{SW}$ 공학수준은 $\mathrm{CMMI}$ 모델의 레벨 2에서 레벨 3 까지의 주요 프로세스 영역의 지표들 을 기반으로 분석이 수행되었다. 이로 인해서 독립 변수의 모집단에 따라 표본이 구분되는 범위 제한 (range restriction)의 문제점이 발생한다. 이런 범위 제한은 조절효과를 식별하는 통계적 파워에 영향 을 미친다. 따라서 향후 CMMI의 레벨 4 와 레벨 5 를 포함한 표본에 대한 추가적인 연구가 필요하다.

본 연구에 사용된 납기편차율은 프로젝트 관리 자들을 대상으로 이루어진 설문조사방식으로 자동 화된 시스템이나 도구를 통해 수집된 자료가 아니 기 때문에 데이터의 정확성에 대한 우려가 존재한 다. 그리고 납기단축이나 지연을 일단위로 측정하 였기 때문에 시간에 대한 절삭 오류가 있을 수 있 다. 또한, 프로젝트의 기간이나 규모를 고려하지 않았다. 예를 들어, 1 개월짜리 프로젝트의 2달 납 기지연과 9 개월짜리 프로젝트의 2달 지연이 동일 하게 취급되었다.

납기편차는 여러 가지 성과변수중 하나의 변수 이다. 따라서 향후에는 본 연구의 결과를 뒷받침 할 수 있도록 비용, 생산성, 품질 및 고객 만족도 와 같은 성과변수들과 어플리케이션 영역, 문화적 요인 등과 같은 다양한 변수들과 관련된 성과 분 석에 대한 추가 연구가 필요하다.

\section{참 고 문 헌}

[1] Harter, D. E., M. S. Krishnan, and S. A. Slaughter, "Effects of Process Maturity on Quality, Cycle Time, and Effect in Software Product Development", Management Science, Vol.46 No.4(2000), pp.451-466.

[2] CMMI CMMI Product Team CMMI for Development, Version 1.3 Software Engineering Institute, Carnegie Mellon University, Pittsburgh, PA, 2010.

[3] Stadish Group, Chaos : A Recipe for Suc ${ }^{-}$ cess, tech. report, Standish Group Int'l, 2009. 
[4] Hefner, R., "Achieving the Promised Benefits of CMM", presentation file, CMMI Technology Conference and User Group, (2005), pp.14-17.

[5] Goldenson, D., J. Herbsleb, After the Appraisal : A Systematic Survey of Process Improvement, its Benefits, and Factors that Influence Success, Technical report CMU/ SEI-95-TR-009, Software Engineering Institute, Carnegie Mellon University, Pittsburgh, PA, 1995.

[6] Daniel Galin and Motti Avrahami, "Are CMM Program Investments Beneficial? Analyzing Past Studies", IEEE Software, Vol.23, No.6 (2006), pp.81-87.

[7] Gibson, D. L., D. R. Goldenson, and K. Kost, "Performance Results of CMMI-Based Process Improvement", Technical Report CMU/ SEI-2006-TR-004, Software Engineering Institute, Carnegie Mellon University, Pittsburgh, PA, 2006.

[8] Brodman, J. and D. Johnson, What small businesses and small organizations say about the CMM, in : Proceedings of the 16th International Conference on Software Engineering, IEEE Computer Society Press, Los Alamitos, CA, (1994), pp.331-340.

[9] El Emam, K. and A. Birk, "Validating the ISO/IEC 15504 measure of software development process capability", Journal of Systems and Software, Vol.51, No.2(2000), pp. 119-149.

[10] El Emam, K. and A. Birk, "Validating the ISO/IEC 15504 measure of software requirement analysis process capability", IEEE Transactions on Software Engineering, Vol. 26, No.6(2000), pp.541-566.

[11] Deephouse, C., T. Mukhopadhyay, D. Gold- enson, and M. Kellner, "Software processes and project performance", Journal of Management Information Systems, Vol.12 No.3 (1995/1996) pp.187-205.

[12] Aguinis, H. and E. Stone-Romero, "Methodological artifacts in moderated multiple regression and their effects on statistical $\mathrm{po}^{-}$ wer", Journal of Applied Psychology, Vol. 82, No.1(1997), pp.192-206.

[13] Miaou, S. P. and H. Lum, "Modeling vehicle accidents and highway geometric design relationships", Accident Analysis and Prevention, Vol.25, No.6(1993), pp.689-709.

[14] Efron, B. and R. J. Tibshirani, An Introduction to the Bootstrap, Chapman and Hall, NY, 1993.

[15] Clark, B. K., "Quantifying the effects of process improvement on effort", IEEE Software, Vol.17, No.6(2000), pp.65-70.

[16] Cohen, J., P. Cohen, S. West, and L. Aiken, Applied Multiple Regression/Correlation Analysis for Behavioral Sciences, third ed., Lawrence Erlbaum, NJ, 2003.

[17] Khaled El Emama Iñigo Garro, "Estimating the Extent of Standards Use : The Case of ISO/IEC 15504", Journal of Systems and Software, Vol.53, No.2(2000), pp.137-143.

[18] Jung, H.-W. and R. Hunter, "The Relationship between ISO/IEC 15504 Process Capability Levels, ISO 9001 Certification and Organization Size : An Empirical Study", Journal of Systems and Software, Vol.59, No.1 (2001), pp.23-41.

[19] Jung, H. W. and D. Goldenson, The Internal Consistency of Key Process Areas in the Capability Maturity Model ${ }^{\circledR}$ for Software (SW -CMM)(CMU/SEI-2002-TR-037).

[20] Ron Ponce, "Steps to On-Time, On-Budget 
Project Delivery", ITworld, 2009, http://www. itworld.com/.

[21] Krasner, H., "Using the Cost of Quality Approach for Software", CrossTalk-The War on Bugs, Vol.11, No.11(1998), pp.6-11. [22] Kitchenham, B., S. L. Pfleeger, B. McColl, and S. Eagan, "An empirical study of maintenance and development estimation accu- racy", Journal of Systems and Software, Vol. 64, No.1(2002), pp.57-77.

[23] Lunneborg, C., Data Analysis by Resampling : Concepts and Applications, Duxbury Thomson Learning, Pacific Grove, CA, 2000.

[24] Montgomery, D. C., G. C. Runger, and N. F. Hubele, Engineering Statistics, John Wiley and Sons Inc., NY, 1998. 


\section{저 자 소 개 $\hat{\forall}$}

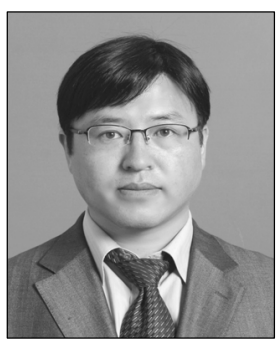

\section{김 승 권 (sgkim@nipa.kr)}

한국외국어대학교 경영정보대학원, MIS석사와 고려대학교 경영학과, MIS 박사학위를 취득 후, 안보경영연구원 u-IT 팀장으로 근무 하였다. 현재는 정 보통신산업진흥원 SW공학센터 수석연구원으로 재직 중이며 관심분야는 소프트웨어품질, $\mathrm{SW}$ 프로세스 평가, 정보시스템 성과평가 등이다.

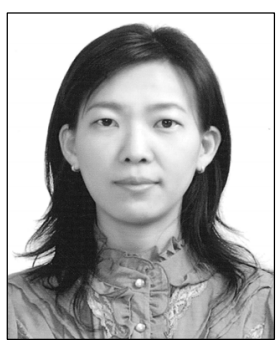

\section{고 병 선 (bsko@nipa.kr)}

숙명여자대학교 컴퓨터과학과 박사 학위 취득 후 현재는 정보통신산업진흥 원 SW 공학센터 책임연구원 재직 중이며, 관심분야는 소프트웨어품질, SW 프로세스 평가, 정보시스템 성과평가 등이다. 